\title{
Well-Being and Human-Animal Interactions in Schools: The Case of "Dog Daycare Co-Op"
}

\section{Laura Elizabeth Pinto}

University of Ontario Institute of Technology

\section{Donna Foulkes}

Peel District School Board

\begin{abstract}
This study draws on Martha Nussbaum's (2000) account of the nature of human wellbeing in order to explore the role of animals in formal education settings. Nussbaum's capabilities approach identifies the ability "to have concern for and live with other animals, plants and the environment" (p. 80) as a necessary component for well-being. Yet, this condition of well-being remains largely unexplored in education despite research that suggests many potential social and health benefits of dog-human interaction. This paper describes the effects of a unique, Canadian school-based cooperative education program in which students work with animals for high school credit. The qualitative research design is based on interviews, students' own stories of the impact of animal interaction - particularly in light of other challenges they faced academically and socially. Research results, support other empirical accounts of positive effects of animals in education settings, and offer insight into the nature of human-animal interaction as a component of well-being within a vocationally-oriented program.
\end{abstract}

Keywords: teaching; education; well-being; human-animal interactions

Laura Elizabeth Pinto, Ph.D., is an Assistant Professor in the Faculty of Education at the University Of Ontario Institute Of Technology in Oshawa, Ontario. She was the recipient of a 2009 Governor General's Gold Medal, and a shortlisted author for the 2013 Speaker's Book Award for her policy-related research.

Email: laura.pinto@uoit.ca

Donna Foulkes (O.C.T) is a teacher at Peel District School Board in Mississauga, Ontario and the recipient of a 2014 OTIP Award of Excellence for Secondary Teachers.

Email: donna_foulkes@rogers.com 


\section{Introduction}

Philosophical attention to human-dog relations can be traced back to the Ancient Greeks in the teachings of Diogenes the Cynic. Some contemporary philosophers - most notably Donna Haraway (2003, 2007) and Raimond Gaita (2005) have explored how dogs fulfill very important relationship functions. Haraway (2007) goes so far as to argue (extending Chris Cuomo's position) that the core ecological, feminist ethical starting point is a "commitment to the flourishing or well-being, of individuals, species, and communities" (Haraway, 2007, p. 134). In this view, compassionate action in relation to companion species such as dogs is crucial to human flourishing. Haraway's (2007) influential work led to inquiry in which dog-human relationships are taken seriously in the humanities and social sciences. This has opened up a new field of inquiry called critical pet studies (for example, Nast, 2006a) provides an exploration of how animals function within everyday human activities and the impacts of that function (Nast, 2006b). ${ }^{2}$

Empirically, recent attention in the social sciences to dog-human relationships has focused on the role of dogs as companion animals (for example, Bauer, Ward \& Smuts, 2009; Smuts, 2006), and social and health outcomes resulting from that role (Burrows, Adams \& Spiers, 2008; Daly \& Morton, 2009; Folse, Minder, Aycock \& Santana, 1994; Haraway, 2007). Children with certain types of special needs such as autism have derived immense benefits from working with $\operatorname{dog}$ s - including their social needs being met, positive mental health outcomes, personal safety, and increased freedom (Anderson \& Olson, 2006; Burrows, Adams \& Spiers, 2008; Friesen, 2010; Folse et al., 1994). With respect to adults, an international, longitudinal study concluded that those who continuously owned a pet were healthier than those who did not (Headley \& Grabka, 2007). The immediate effects of dog-human interaction reported included stress buffering and relaxation, which may have an impact on other human health indicators including decreased blood pressure and decreases in heart disease risk factors (Virués-Ortega \& Buela-Casal, 2006). Other research concluded that pets led to greater interaction with other people and may have resulted in increased civic engagement by way of social connections made through animals (Wood, Giles-Corti \& Bulsara, 2005).

Additional empirical research has investigated the effects of various forms of dog inclusion in formal education settings that range from post-secondary institutions to early childhood education settings. Firstly, small-scale research about the use of therapy dogs in postsecondary exam settings concluded that dog interaction reduced test-taker stress (Bell, 2013; Reynolds \& Rabshutz, 2011). In these programs, therapy dogs were brought to university and college campuses during examination periods, and kept with their handlers in designated spaces near campus. Students had the option of visiting the therapy dogs. This type of program has been

\footnotetext{
${ }^{2}$ A full exploration of critical pet studies is beyond the scope of this paper. While critical pet studies describes, on the one hand, the benefits of human-animal interaction, it also exposes ways in which contemporary human-animal relations can displace concern for other humans. For example, Nast (2006b) describes how the booming pet insurance industry has thrived while many human citizens cannot afford health care or insurance. Nast (2006b) also critiques the ways in which greenspace dedicated to pets in densely-populated communities seems to take precedence over parallel dilemmas about the lack of greenspace in low-income urban communities.
} 
used successfully at the University of Toronto, the University of Saskatchewan, Carleton University in Ottawa, University of Manitoba, Memorial University of Newfoundland, University of Connecticut, Massachusetts Institute of Technology (MIT), Yale Law School, and many others. Both anecdotal and empirical accounts of these programs suggest promising contributions to individual students' well-being and appear to be consistent with the physiological health benefits of dog-human interactions described earlier.

Secondly, small-scale research about the use of therapy dogs in early childhood settings confirmed many positive impacts, ranging from gains in literacy development among reluctant readers (Francis, 2009; Friesen, 2009, 2010; Jalongo, 2005; Jalongo, Astoria \& Bomboy, 2004) to positive, pro-social classroom behavior when dogs were present (Anderson \& Olson, 2006; Beetz, 2013; Kotrschal \& Ortbauer, 2003; McNicholas \& Collis, 2000). Similarly, Beetz (2013) reported a growing trend in Europe of teachers bringing their dogs into classrooms, and her research pointed to various social interaction benefits within those classrooms. In North America, specialized dog training and certification through Reading Education Assistance Dogs (READ) is available. In 2012, READ had 2,000 registered teams across the United States, in three Canadian provinces, in Europe, and elsewhere (Schwartz, 2012). In dog-supported literacy programs like READ, children read to the therapy dogs in schools and libraries with no adult intervention as a means of practicing literacy. Children who were already struggling with reading tended to take more risks (for example, sounding out difficult words) when reading to a dog rather than a person, thus helping them to build reading proficiency and vocabulary (Jalongo, 2005). While only documented anecdotally, the pleasure and excitement that the children derived from working with dogs may contribute to more positive attitudes towards reading and literacy. Animal inclusion in formal education is not a novel concept. Dewey's (1907) philosophy of education emphasizes the importance of natural settings and authentic learning as central to meaningful education. He was specific about the value of direct contact with the natural world, including plants and animals:

No number of object-lessons, got up as object-lessons for the sake of giving information, can afford even the shadow of a substitute for acquaintance with the plants and animals of the farm and garden, acquired through actual living among them and caring for them. No training of sense-organs in school, introduced for the sake of training, can begin to compete with the alertness and fullness of sense-life that comes through daily intimacy and interest in familiar occupations. (Dewey, 1907, pp. 24-25).

Like Dewey (1907), philosopher of education Noddings (2003) emphasizes the need for pedagogies of places and nature in all school curricula, based on the biophilia hypothesis: that human beings have an inherent need to affiliate with nature beyond the need for food. Cultivating healthy relationships with nature in educational settings, she explains, contributes to happiness and the fulfillment of a basic need (Noddings, 2003). While she proposes that such education ought to take place in natural settings, she acknowledges that this may not always be feasible. Alternately, she recommends bringing nature into schools through gardens, pets, and other methods. She cautions, however, that "delight" must precede tedious tasks: when affiliation with nature begins as a chore, learners may lose their natural joy and enthusiasm. In her view, responsibility must be phased in as learners become more involved with and invested in nature something that can only happen by allowing an initial wonder to flourish. Noddings (2003) also encourages teachers to have faith in incidental learning that occurs as learners explore the world in/with nature.

The philosophical thought and empirical research just described point to unique ways in 
which dog-human interactions can contribute to individual well-being in school settings. Yet despite growing interest among social scientists and some educators about the positive effects of dogs in education, it has received relatively little attention among contemporary philosophers of education. This paper takes up Dewey's (1907) and Noddings' (2003) calls for natural education, and considers how the integration of animals in school settings play a role in well-being by examining students' self-reported perceptions after a semester-long program in which they worked with dogs.

In what follows, we explore how animals in school settings affect the well-being of those in the school community, especially students. To do so, we begin by situating our work in Nussbaum's (2000) capabilities approach as a substantive account of well-being. Next, we describe the context in which the research took place, and describe the methods used to capture students' perceptions of working with dogs. The data presented are small in scale, and we limit our work to a descriptive (not normative) account of the impact of dogs in formal education. Finally, we discuss themes that emerged from the data in relation to educational aims, Nussbaum's (2000) capabilities, and the theoretical positions of Dewey (1907) and Noddings (2003).

\section{Cultivating human flourishing as well-being: Nussbaum's capabilities approach}

Well-being is a loosely defined, fluid concept (Jaggaer, 2006; Qizilbash, 1998; Tiberius, 2004). For the purpose of this paper, Nussbaum's (2000) capabilities approach offers a substantive view about the nature of well-being, including a detailed account of its components. Nussbaum's (2000) Aristotelean framework posits that well-being is human flourishing: people live well when engaged in essential human functions, which she terms capabilities. The central social goal in any community or society should be understood in terms of getting citizens above the minimum capability threshold (Nussbaum, 2000). She is very clear that the capabilities ought to be treated as ends for all citizens.

Nussbaum (2000) characterizes her capabilities approach as a cross-cultural normative account of basic constitutional principles that should be respected by all governments as a bare minimum for human dignity. She developed the framework through consultations with various international women's development projects and groups. Nussbaum's (2000) resulting ten capabilities are:

1. Life (living a life of normal quality and length)

2. Bodily health

3. Bodily integrity (moving freely from place to place and security against violent assault, opportunities for sexual satisfaction and choice in matters of reproduction)

4. Senses, imagination, and thought

5. Emotions (having attachments to things and people outside the self; to emotional development not blighted by fear and anxiety)

6. Practical reason (including freedom of conscience and religious observance)

7. Affiliation

8. Other species

9. Play

10. Control over one's political and material environments

Each capability represents a necessary, but insufficient, condition for human flourishing and well-being (Nussbaum, 2000; Tiberius, 2004). Nussbaum (2000) emphasizes that they are 
separate and independent of one another: one capability cannot be satisfied by providing a larger amount of another. Yet, all, she argues, are central to well-being.

For this paper, we narrow our concern to the eighth condition concerning other species: "to have concern for and live with other animals, plants and the environment at large" (Nussbaum, 2000, p. 80). Nussbaum (2000) conceives of this capability broadly - such that it includes all interaction with the natural world and is not restricted to companion animals. She added this capability at the insistence of Scandinavian participants "who said that this was something without which, for them, no life could be truly human" (Nussbaum, 2000, p. 157). Her findings are consistent with Noddings' (2003) position that interaction with the natural world is a basic human need. For example, Norway actualizes this capability by protecting regions (keeping them free of habitation and development) so that people can enjoy the solitude in the forest (Nussbaum, 2000).

Nussbaum (2000) describes "other species" as the most controversial of the capabilities. She reports that participants from other parts of the world questioned the capability and its relevance. Yet, she came to believe that it has an important role to play in human flourishing though acknowledged the impossibility of achieving political consensus. She speculates that those who object to including this capability lack experience in or with the natural world.

Whereas Nussbaum's (2000) examples of interaction with the natural world are based on project participants' accounts of it, critical pet studies scholars suggest that companion animals (especially dogs) have a specific function in Western, industrialized societies. Declines in family size, aging populations, and isolated work and leisure activities result in human alienation that takes the form of loneliness and fewer place-based communities (Nast, 2006b). Companion animals fill that void by offering companionship and provide a means to enter a different type of social community such as a dog park (Nast, 2006b). In this way, animals can (and do) contribute to well-being by providing a means of social bonding and a sense of belongingness.

\section{Policy context: Multiple educational aims}

The present research is situated in the province of Ontario, where curriculum oversight via prescriptive policy documents is the responsibility of the provincial Ministry of Education (OMoE). Since the late 1990 s, the Ontario MoE has increasingly emphasized vocational aims in education policy (Hyslop-Margison \& McKerracher, 2008; Pinto, 2012, 2014). One manifestation of Ontario's vocational agenda is emphasis on cooperative education. The mechanics of cooperative education programs and learning outcomes are prescribed in curriculum policy documents though schools have authority to develop thematic, two or four credit cooperative education around a particular industry or occupational group. In these arrangements, students receive some in-class training combined with co-operative education placements in workplaces outside of the school - for example, a student may have a placement in a local hospital, a retail store, an office, and so on.

Ontario's emphasis on vocational education represents one of many educational aims. Philosophers of education have long emphasized that multiple educational aims can and should coexist (Hodgkinson, 1991). Most philosophers of education agree that individuals and systems must balance those aims in the best interest of students (Hodgkinson, 1991). For example, Noddings (2003) describes the value of educating for both "private" life (making a home, loving places and nature, parenting, character and spirituality, and interpersonal growth) and for "public" life (preparing for work, educating for community, democracy, and service). Within her 
schema, well-being as an educational aim would be situated in the private dimension, but not at the expense of preparation for public life.

Over-emphasis on any single aim has implications on what forms of knowledge are valued and what "counts" as legitimate learning. Noddings (2003) argues that "aims talk" in contemporary education (that is, a concern with narrow forms of achievement captured by standardized testing) must be reconsidered in favour of a concern for human flourishing as a central educational goal. "If we believe that people should have the chance to live happy and fulfilling lives," she writes, narrow aims "will simply not do" (Noddings, 2003, p. 84). Rather, she advocates happiness as a central educational ideal. Happiness depends on human flourishing, which is tied to well-being.

Some argue that Ontario's strong vocational education - despite its legitimacy as an educational aim - places disproportionate emphasis on the economic aspects of public life (Hyslop-Margison \& McKerracher, 2008; Pinto, 2014). Along these lines, Noddings (2003) expressed a concern that this form of education directed towards economic ends narrows educational experiences in ways that diminishes a pursuit of well-being. The framing of vocational education aims affects how students view their roles as workers and citizens (Pinto, 2012). The framing can also contribute to or detract from the cultivation of well-being, particularly when both the official and hidden curriculum position students strictly in economic terms (Pinto, 2012).

\section{Research Context}

The research site was a vocationally-oriented high school in a large, suburban Ontario school board. The school provides a number of unique programs to serve students with exceptionalities. Typically, these programs offer a variety approaches to accommodate those students.

The school studied, Howth Castle Collegiate ${ }^{3}$ strongly encourages students to participate in cooperative education programs in keeping with both the school's and provinces vocational focus. A challenge faced by the Howth Castle Collegiate was ensuring that all students - including those with exceptionalities - had meaningful cooperative education opportunities. Given the Howth Castle Collegiate relatively large population of students with exceptionalities, placement options in the community were limited, since, students may require accommodations that are not feasible outside the school. The program studied in this research, Dog Daycare Co-op ${ }^{4}$, was developed to address this need. In-school work placement opportunities (e.g., dog daycare) offered an option to accommodate students who may not thrive in a community-based placement outside the school. Started in September, 2011, Dog Daycare Co-op was designed to give students a balance of academic credits and hands-on learning in an on-site dog daycare service. The school, which had struggled with declining enrolment, also saw the dog daycare program as a means to attract new students. In its first year, the program had 10 students; in year two the enrolment increased to program's maximum capacity of 15 per semester.

Students enrolled in Dog Daycare Co-op during this research began with a month-long formal curriculum that included field trips, webinars, and guest speakers to learn about dog handling, animal CPR/safety, and basic grooming (bathing, brushing). A small business

${ }^{3}$ In accordance with REB requirements, a pseudonym has been used for the school.

${ }^{4}$ A program pseudonym has been used to ensure research participants' anonymity. 
curriculum helped them understand how to establish and maintain processes typical of a dog daycare or grooming workplace outside school settings. This curricular arrangement also supports the school's vocational designation while adhering to the government's strong emphasis in the official curriculum of a career-related study.

For the remainder of the semester, students studied business concepts and animal behaviour two days a week, and worked with dogs by running a school-based dog daycare three days a week. The dogs attending the daycare belonged to school staff members who paid \$200 each per semester (about $\$ 5$ a day) for three-day-a-week dog care. ${ }^{5}$ All funds went back into the program. At the end of the semester, students earned four credits towards their high school diploma.

The program pair one dog with one student to ensure dog "enrolment" corresponds to the number of students in any given semester. For the safety of both humans and dogs, all dogs are screened before they are admitted to the program, and any dogs that show signs of unsafe behavior is removed from the program. The nature of the program ensures all students interact with dogs and other students - though the structure differs from the ecological inquiry/experience in natural spaces that Nussbaum (2000), Noddings (2003) and Dewey (1907) hold as the ideal. Rather than exploring nature outside of the school, nature is brought into school settings by way of dogs. Noddings (2003) acknowledges this form of natural education as a legitimate alternative to overcome the practical problems of exploring nature outside of the school, especially in urban settings.

\section{Research Methods}

The paper reports on research that took place during Dog Daycare Co-op's second year of operation (2012-2013). The researchers obtained research ethics board (REB) approval from the school district and the principal investigator's (PI) University. Signed parental consent to participate in the study was obtained at the beginning of the semester by the program's teacher. The parents of all students enrolled in the program received and signed the informed consent letter distributed by the teacher. Parental consent was obtained because students enrolled in the program had not reached the age of majority, and many of them had been identified with exceptionalities. Students could verbally dissent from participation. A total of 15 interviews with students aged 15 to 17 years old at the end of their semester-long participation in the Dog Daycare Co-op program were conducted. All students enrolled in the program that semester were interviewed during class time, and none of them verbally dissented from participation.

The larger (2012- 2013) research project also included the collection of quantitative data in the form of the Empathy Index for Children and Adolescents (IECA) (Bryant, 1982) ${ }^{6}$. This

\footnotetext{
${ }^{5}$ In 2014 , the program structure was changed to a fee of $\$ 250$ that includes grooming session with a professional groomer who provides students enrolled in the program a 4-hour grooming theory lesson.

${ }^{6}$ At the beginning of the semester, prior to working with the dogs, students participating in this research completed the IECA Empathy Index for Children and Adolescents (IECA) a 22-item self-report questionnaire developed and validated by Bryant (1982) to assess dispositional empathy in children aged 6 or older, and has been used with individuals in their adolescent years (see, for example, De Wied, Maas, Van Goozen, Vermande, Engels, Meeus, Matthys \&
} 
paper limits itself to the interview data for several reasons. First, our concern with student perceptions of well-being for the purpose of this paper was addressed through the interview questions, whereas the quantitative portion of our research was concerned with empathy. Second, interviews allow students' voices to come through, offering a detailed narrative account of their unique experiences and perceptions. We believe that those student perceptions are central to understanding how working with dogs affected their well-being.

One-on-one interviews were conducted by the PI in Dog Daycare Co-op's loft area during class time. The loft is located directly above the classroom area, which allowed the PI to interact and converse with students without distractions or interference from teachers and students. Interviews were guided by a semi-structured protocol containing three broad questions aimed at understanding students' self-reported perceptions about the program, and prompts used to encourage participants to share specific examples or elaborate on points made.

Interviews were recorded and transcribed. Analysis of transcripts followed Creswell's (2013) recommendations for constant comparative analysis typically used for grounded theory studies in order to identify themes. We simultaneously coded and analyzed data, identifying potential themes that spanned across multiple transcripts. We noted passages that characterized emergent themes using coloured markers so that the data would remain in context. We continued to refine comparisons until strong themes emerged across transcripts. Finally, we compared constant-comparative themes to the literature (especially Nussbaum's capabilities) and made note of connections.

\section{Students' experiences and perceptions}

The interviews with 15 students aged 15 to 17 years old at the end of their semester-long participation in Dog Daycare Co-op revealed two, related themes: (a) vocational musings, and (b) bonding/belongingness. In this section, we will discuss each theme in relation to the literature.

\section{Vocational musings}

In the interviews, students linked their experience to future occupational goals without researcher prompting. Some reported that the experience made them wish to have a career working in dog care, others discussed how they enjoyed the experience but it led them to conclude that working with animals as an occupation was not for them. However, even those who concluded they prefer not to work with dogs emphasized that they enjoyed the program and hoped to continue to spend time with dogs as pets. For example, one student began by emphasizing that she enjoyed interacting with the dogs, but "it's helped me definitely decide not to work in dog daycare." Another student began by stating she thought the program "would be boring," but participation "changed me to work in the dog industry." Another stated that prior to the course, he didn't know what he wanted to do, but participation "helped me figure what I wanted to do. Work with dogs." The emphasis on occupation in participant responses may be a result of several factors. First, the

Goudena, 2007). The IECA was re-administered at the end of the semester. A pre- and post-test analysis revealed no significant changes in empathy on IECA survey items when analyzed quantitatively. The survey instrument, methods, and results of quantitative analysis are available at http://laurapinto.weebly.com/uploads/2/4/8/4/24842679/dog-empathy-table.pdf 
setting happens to be a vocational school, and Dog Daycare Co-op is a cooperative education course, so it is necessarily tied to occupation. The curriculum is overtly tied to career choices based on the credits assigned to the program, and these outcomes are established by the Ontario MOE. This official curriculum may have influenced students' perceptions about the nature of their participation.

\section{Bonding/belongingness}

The second and more prominent theme that emerged from interviews was participants' reports of bonding and belongingness that resulted from their participation in Dog Daycare Co-op. Almost all students called attention to "friendship" or "bonds" with human and animal as well as other students an important feature of their participation, and this led them to feel a sense of belonging. The collaborative nature of the daily care of dogs allowed students to interact with dogs and other students. In a representative quote, a male student stated, "the best part of participating was that I got new friends" - emphasizing that when he said "friends" he was referring to both humans and dogs. Another student talked about how the acts of grooming and training dogs resulted in bonding with the dog assigned to her. Another explained that she would recommend the program to other students because, "it'll make you feel loved by dogs." These quotations reflect criteria for well-being envisioned by Nussbaum (2000).

Several participants described "feeling loved," suggesting the importance of affective and social aspects of dog interaction. Perhaps the most striking aspect of "feeling love" was revealed in two students' responses. Both of these students self-reported that they had experienced difficult times in school. One female had a self-described history of truancy and talked about how the program changed her interest in attending school. In her own words, "you bond so well with the students and dogs" that "dogs make school worth coming to...before this program, I often skipped school." She explained that knowing the dogs would be there expecting to see her gave her inspired motivation to attend. Her reported sense of belongingness was so powerful that it increased her level of engagement in school.

Another student disclosed that she experienced anxiety and depression and that she had a tendency to be late for school. She reported that she "doesn't like people", something she claims made school an unpleasant experience. She went on to explain that she developed a very close bond with one dog in the program (Finnegan ${ }^{7}$ ). The relationship she had with the dog motivated her to want to come to school and to arrive on time. During the interview, she cried when she discussed the program coming to an end because her regular contact with Finnegan would end. Strong student-dog bonds like this one had occurred in earlier iterations of Dog Daycare Co-op. In fact, teachers reported that one student-dog bond was so strong that the dog pined for the student when the student's time in the program ended. These experiences and examples demonstrate direct increases in perceived well-being (in the form of belongingness) that were so strong, students felt motivated to attend school because of these important connections to others.

The student-dog bonds described extended beyond caring for another creature. The development of compassion speaks to an element of well-being and ties to the core ecological, feminist ethic (Haraway, 2003). According to students, those bonds were grounded in substantive learning about dogs and their ways of being. Several students talked about their discoveries relating to the nature of dogs and their understandings of care and empathy. One

${ }^{7}$ In accordance with REB requirements, pseudonyms have been used. 
student articulated this in precise terms: "The most important thing I learned in this program was having more empathy and compassion for the dogs." This type of bonding is consistent with Nussbaum's "other species" capability, and suggests the type of natural flourishing towards which this capability strives.

The importance of play that happens to be another one of Nussbaum's 2000 capabilities, was raised by almost all participants. Its importance was in relation to the role of human-dog play as enjoyment consistent with Noddings' 2003 assertions about the importance of joy in education through nature. Several students discussed the wonder of learning to decipher dogs' play styles (for example, what a dog's "bow" communicates to other dogs and people). One student, who claimed she discovered a "hidden skill" (her words) for communicating with both dogs and people, stating "don't mistake 'play with dogs' for 'understanding how [sic] dogs are like, their feelings and reactions." This group of statements points to students' interest in learning to communicate with and understand the dogs in the group. Furthermore, the statements reinforce Noddings' (2003) views on biophilia as well as Haraway's (2007) and Nussbaum's (2000) claims about the nature and importance of companion species relationships because the students describe ways in which relationships in dogs enriched learning.

Multiple participants reported observing other students being "calmed" by dogs. One female in the class described a classmate who easily "gets angry," but whom participation "helps to keep calm." She described how the classmate was able to overcome feelings of anger and aggression by spending time focusing on and interacting with his assigned dog. This theme is certainly consistent with much of the empirical data on the positive calming physiological effects of dogs (Virués-Ortega \& Buela-Casal, 2006). Moreover, the well-being of individuals and the entire group was enhanced by helping students have more positive and calming interactions based on the effects of dogs on their dispositions and behaviour.

While bonds between individual students and their assigned dogs contributed immensely to a sense of belongingness, it was not at the expense of bonding with other humans in the group. Clearly, the structure of the program - including the time for play, to the development of compassion, caring for others and interaction with multiple species - make specific contributions to participants' well-being in school.

\section{Conclusion}

While Dog Daycare Co-op has a clear vocational mandate, students' perceptions suggest that the program served an important function in contributing to their well-being through interaction with human and animal others. The bonding had profound effects on some students: especially the two 16-year-olds who reported that their bonds with dogs motivated them to attend and arrive at school on time. Students' reported feelings of belonging and "feeling loved" suggest that meaningful interactions with companion species may contribute to the kind of human flourishing that Nussbaum (2000) and Noddings (2003) describe in their normative accounts of well-being.

The findings also suggest that substantive well-being can be pursued within and against the backdrop of vocationally-focused education. Students' perceptions support Noddings' (2003) views about the value of educating for both "private" life (building relationships as well-being) and for "public" life (vocational musings evident in the analysis).

This is not to suggest that all aspects of Dog Daycare Co-op follow conceptions of wellbeing associated with the work of Nussbaum (2000), Noddings (2003), and Dewey (1907) relating to natural education. The program itself is structured in a way that conforms to Ontario's 
prescriptive curriculum guidelines, and emphasizes economic/vocational ends consistent with provincial educational directions. Interviews revealed that the "official curriculum" fulfilled Noddings' (2003) conception of education for "public" life and Dewey's ideal of "introduce[ing] into the school something representing the other side of life - occupations which exact personal responsibilities and which train the child with relation to the physical realities of life" (Dewey, 1907, pp. 25-26). Interview analysis demonstrated that students had internalized the vocational learning, but certainly this occurred alongside the cultivation of capacity for "private" life (Noddings, 2003), including enriching bonds with others that contributed to their well-being.

The research points to many further avenues for empirical and philosophical inquiry related to the inclusion of animals in school settings. Continued research with subsequent Dog Daycare Co-op cohorts would allow for insight into how representative this group of participants' experiences are of the program as a whole. Further research on similar programs operating in other districts would offer greater insight into the effects of dog-human interaction in school settings. Critical analysis of school-based dog daycare using the methods and approaches of critical pet studies (Nast, 2006a, 2006b) would call attention to a broad array of social implications arising out of a program like this one. Such research could extend important discussions about whether classroom-based curriculum, which is vocational in nature, has an obligation to address the questions raised in critical pet studies in an age-appropriate manner. While Dog Daycare Co-op may address some students' needs for belongingness, further investigation could address whether the presence of dogs creates a "celebration of 'innocence' diverting critical interest away from the non-innocent world of pressing human concerns" (Nast, 2006b, pp. 324-325) such as use of resources for dog daycare (rather than child daycare) and their benefit to the community. Critical pet scholars might also explore the commoditized nature of animal inclusion - dogs are brought into the school not only for altruistic purposes, but as part of a commercial transaction. As such, the program's structure can be viewed as contributing to the normalization of neoliberal and consumerist practices in a public institution instead of promoting altruist care. Further research about the hidden curriculum conveyed by the program that treats care as a financial transaction yield suggestions for future program revisions and development. 


\section{References}

Anderson, K.L, \& Olson, M.R. (2006). The value of a dog in a classroom of children with severe emotional disorders. Anthrozoös: A Multidisciplinary Journal of the Interactions of People \& Animals, 19(1), 35-49.

Bauer, E., Ward, C \& Smuts, B. (2009). Play like a puppy, play like a dog. Journal of Veterinary Behavior: Clinical Applications and Research, 4(2), 68-69.

Beetz, A. (2013). Socio-emotional correlates of a school dog-teacher-team in the classroom. Frontiers in Psychology, 4, 1-7.

Bell, A. (2013). Paws for a study break: Running an animal assisted therapy program at the Gerstein Science Information Centre. Partnership: The Canadian Journal of Library and Information Practice and Research, 8(1), 1-14.

Bryant, B.K. (1982). An index of empathy for children and adolescents. Child Development, 53, 413-425.

Burrows K.E., Adams C.L. \& Spiers J. (2008). Sentinels of safety: service dogs ensure safety and enhance freedom and well-being for families with autistic children. Qualitative Health Research, 18(12), 1642-1649.

Creswell, J. W. (2013). Qualitative inquiry and research design: Choosing among five approaches (3rd Ed). Thousand Oaks, CA: Sage.

Daly, B. \& Morton, L.L. (2009). Empathic differences in adults as a function of child and adult pet ownership and pet type. Anthrozoös: A Multidisciplinary Journal of the Interactions of People \& Animals, 22(4), 371-382.

Dewey, J. (1907). The school and society. Chicago, IL: University of Chicago Press.

De Wied, M., Maas, C., Van Goozen, S., Vermande, M., Engels, R., Meeus, W., Matthys, W. \& Goudena, P. (2007). Bryant's Empathy Index: A closer examination of its internal structure. European Journal of Psychological Assessment, 23(2), 99-104.

Folse, E. B., Minder, C. C., Aycock, M. J., \& Santana, R. T. (1994). Animal-assisted therapy and depression in adult college students. Anthrozoös: A Multidisciplinary Journal of the Interactions of People \& Animals, 7(3), 188-194.

Francis, A. (2009). Thursdays with MacGyver. The benefits of a library therapy dog. Children and Libraries: The Journal of the Association for Library Services to Children, 7(2), 5052.

Friesen, L. (2010). Exploring animal-assisted programs with children in school and therapeutic contexts. Early Childhood Education Journal, 37(4), 261-267.

Friesen, L. (2009). How a therapy dog may inspire student literacy engagement in the elementary language arts classroom. LEARNing Landscapes, 3(1), 105-121.

Gaita, R. (2005). The philosopher's dog: Friendships with animals. New York, NY: Random House.

Jaggar, Alison M. (2006). Reasoning About Well-Being: Nussbaum's Methods of Justifying the Capabilities. Journal of Political Philosophy, 14(3), 301-322. 
Jalongo, M.R. (2005). What are all these dogs doing in school? Using therapy dogs to promote children's reading practice. Childhood Education, 81(3) 152-158.

Jalongo, M.R., Astorino, T. \& Bomboy, N. (2004). Canine visitors: The influence of therapy dogs on young children's learning and well-being in classrooms and hospitals. Early Childhood Education Journal, 32(1), 9-16.

Haraway, D. (2003) The companion species manifesto: Dogs, people, and significant otherness (Vol. 1). Chicago, IL: Prickly Paradigm Press.

Haraway, D. (2007). When species meet. Minneapolis, MN: University of Minnesota Press.

Headey, B. \& Grabka, M.M. (2007). Pets and human health in Germany and Australia: National longitudinal results. Social Indicators Research, 80(2), 297-311.

Hodgkinson, C. (1991). Educational leadership: The moral art. New York, NY: SUNY Press.

Hyslop-Margison, E. J., \& McKerracher, A. (2008). Ontario's guidance and career education program: A democratic analysis. Journal of Education and Work, 21(2), 133-142.

Kotrschal, K. \& Ortbauer, B. (2003). Behavioural effects of the presence of a dog in the classroom. Anthrozoös: A Multidisciplinary Journal of the Interactions of People \& Animals, 16(2), 147-159

McNicholas, J., \& Collis, G.M. (2000). Dogs as catalysts for social interactions: Robustness of the effect. British Journal of Psychology, 91(1), 61-70.

Nast, H.J. (2006a). Critical pet studies. Antipode 38(5), 894-906.

Nast, H.J. (2006b). Loving... whatever: alienation, neoliberalism and pet-love in the twenty-first century. ACME: An International E-Journal for Critical Geographies 5(2), 300-327.

Noddings, N. (2003). Happiness and education. Cambridge: Cambridge University Press.

Nussbaum, M. (2000). Women and human development: The capabilities approach. Cambridge: Cambridge University Press.

Pinto, L.E. (2012). Curriculum reform in Ontario: 'Common Sense' processes and democratic possibilities. Toronto, ON: University of Toronto Press.

Pinto, L.E. (2014). The cultural myth of the entrepreneur: 2014 remix. Our Schools/Our Selves, 23 (4) (105), 23-34.

Qizilbash, M. (1998). The concept of well-being. Economics and Philosophy 14(1), 51-73.

Reynolds, J.A. \& Rabschutz, L. (2011). Studying for exams just got more relaxing: Animalassisted activities at the University of Connecticut Library. College \& Undergraduate Libraries, 18(4), 359-367.

Schwartz, M. (2012, February 6). Therapy dogs' presence steadily grows in libraries. Library Journal. Retrieved from: http://lj.libraryjournal.com/2012/02/library-services/therapydogs-presence-steadily-grows-in-libraries/\#_ 
Smuts, B. (2006). Between species: Science and subjectivity. Configurations, 14(1/2): 115-126.

Tiberius, V. (2004). Cultural differences and philosophical accounts of well-being. Journal of Happiness Studies, 5(3), 293-314.

Virués-Ortega \& Buela-Casal, G. (2006). Psychophysiological effects of human-animal interaction: Theoretical issues and long-term interaction effects. The Journal of Nervous and Mental Disease, 194(1), 52-57.

Wood, L., Giles-Corti, B. \& Bulsara, M. (2005). The pet connection: Pets as a conduit for social capital? Social Science \& Medicine, 61(6), 1159-1173. 